\title{
Assessing the Queuing Process Using Data Envelopment Analysis: An Application in Health Centres
}

Komal A. Safdar, Ali Emrouznejad', Prasanta K. Dey

Aston Business School, Aston University, Birmingham, UK

\begin{abstract}
Queuing is one of the very important criteria for assessing the performance and efficiency of any service industry, including healthcare. Data Envelopment Analysis (DEA) is one of the most widelyused techniques for performance measurement in healthcare. However, no queue management application has been reported in the health-related DEA literature. Most of the studies regarding patient flow systems had the objective of improving an already existing Appointment System. The current study presents a novel application of DEA for assessing the queuing process at an Outpatients' department of a large public hospital in a developing country where appointment systems do not exist. The main aim of the current study is to demonstrate the usefulness of DEA modelling in the evaluation of a queue system. The patient flow pathway considered for this study consists of two stages; consultation with a doctor and pharmacy. The DEA results indicated that waiting times and other related queuing variables included need considerable minimisation at both stages.
\end{abstract}

Keywords: Data Envelopment Analysis, Healthcare, Queuing, Patient Flow, Appointment Scheduling System.

\section{Introduction}

The existence of any nation is a function of the survival of its citizens, which in turn depends on the provision of the health care facilities (Ramanathan 2005; Adeleke et al., 2009). Factors such as variability in patients' medical complaints or reason for visit as well as corresponding diagnosis proposed by doctors after close examination daily and weekly workload fluctuations and multiple objectives within and between departments, make it extremely challenging to understand the operational performance of a large hospital subsystem (Matta and Patterson, 2007). Given the increasing cost pressures, complexity of diseases and increased demand of quality and efficacy, efficient and smooth provision of health services is becoming extremely important (Ramanathan 2005; Mehandiritta 2011). Despite these challenges, there is a need of continuous assessment of the operational efficiency of hospitals which allows the decision-makers to develop a better understanding of the management effectiveness, and to provide valuable insights into improving resource allocation (Chuang et al., 2011).

\footnotetext{
${ }^{1}$ Corresponding author:

Ali Emrouznejad, Professor and Chair in Business Analytics, Aston Business School, Aston University, Birmingham, UK, a.emrouznejad@aston.ac.uk
} 
There are a number of aspects which indicate fast and efficient services provided by the health organizations around the globe. Some of these include patient throughput, short length of stay at the clinic and low clinic overtime, while maintaining adequate staff utilization rates and low physician idle times. In addition to these factors, low patient waiting time is a significant aspect which demonstrates efficient and effective health services. Excessive waiting and service times cause dissatisfaction among the patients, leading to reduced customer demand, causing them to leave the system without receiving the service and can constitute a barrier to effective treatment (Jun et al., 1999; Biju and Naeema 2011; Yeboah \& Thomas 2010; Silva and Serra 2008).

\subsection{Excessive Queuing in Developing Countries}

The developing countries of the world face multiple challenges mainly including high population, low literacy rates, high rate of incidence of diseases and inadequate funding. The healthcare delivery systems in these countries face various issues such as huge number of patients, shortage of physicians and other health personnel, lack of training and post-training supervision of health personnel, late arrival of doctors, lack of medical equipment and aftercare facilities, and improper allocation of resources; resulting in overloading in health facilities and long wait times, making the life of patients quite miserable (Babes and Sarma 1991; Manzi et al 2014; Mensah et al 2015). Almost all large public hospitals in developing countries provide primary and tertiary care facilities to all patients. They do not have General Practitioner (GP) referral systems, unlike developed nations and even for a minor ailment, the patients have to visit these large unwieldy hospitals. Also, the patient flow system in these hospitals consists of different stages from entry till exit. Behind simple broad pathways, immense paper work, and cumbersome admission and lay procedures are involved. Due to these factors, patients experience excessive queuing and the management faces the challenge of dealing with excess demand. There is a need to assess the efficiency of the queuing system by identifying factors which cause long waiting at each stage.

Most of the healthcare institutions in the developed world have a dedicated Appointment System (AS), which not only assists the hospital management to deal with patient flow and organize resources, but also facilitates patients. In numerous developing nations, such as Pakistan, almost all health organizations lack a set Appointment System, resulting in long waiting. The former works have emphasized on evaluating and improving patient flow and scheduling (Bhattacharjee and Ray, 2014) in different departments of the hospital including inpatients (Proudlove et al., 2007), outpatients (Cayirli and Veral, 2003), emergency (Gul and Guneri, 2015) and surgical/operations (May et al., 2011). However, there are only a limited number of studies which particularly assessed the flow of walk-in patients in health centres (Fetter and Thompson 1966; Rising et al., 1973; Ashton et al., 2005; Cayirli and Gunes 2014). Additionally, these few studies have been conducted in developed countries only and there are almost negligible studies in the developing world. Therefore, there is a dire need to 
evaluate a queue system such that it caters for the requirements whilst keeping in mind the present idiosyncrasies; that is all patients are walk-in and Appointment Systems are non-existent.

\subsection{Main Aim and Objectives of the Current Study}

Various studies have been conducted which emphasized on performance assessment of health institutions with respect to patient flow (Bhattacharjee and Ray 2014). There are a number of different Operational Research (OR) techniques which have been used to assess the queuing problems or patient flow systems including, Queuing theory (Fomundam and Hermann, 2007; Mayhew and Smith, 2008; Lakshmi and Sivakumar, 2013), Discrete-event Simulation (Jun et al., 1999; Cayirli and Veral, 2003; Gunal and Pidd, 2010; Konrad et al., 2013), System Dynamics (Lane et al., 2000; Brailsford et al., 2004; Gunal 2012) in addition to others. However, none of the queue management studies have used the performance measurement technique of Data Envelopment Analysis (DEA).

DEA is a non-parametric approach, used to assess the efficiency of a decision-making unit (DMU) by modelling the relationship between multiple inputs and outputs (Chuang et al., 2011; Pelone et al., 2015). DEA has proven to be an effective and versatile tool for health care efficiency measurement (O’Neill et al., 2008), in addition to applications in other fields such as education, banking, computer engineering, tourism, sports and some others. Liu et al (2013) provide a detailed survey of DEA applications in various fields. Among various healthcare applications, DEA has been mostly applied to the efficiency comparison of hospitals (Nunamaker 1983; Parkin and Hollingsworth, 1997; Ouellette and Vierstraete, 2004; Akazili et al., 2008; Flokou et al., 2011; Kawaguchi et al., 2014). These studies have included a varied set of inputs and outputs in the DEA model which best represent the efficiency criteria. However, none of the previous studies included the queuing problem as part of the performance assessment. Also, very few studies have been carried out in the developing world. The present study represents a novel application of DEA for assessment of the queuing system of a large public hospital in a developing country.

The current study specifically aims at the formulation of a DEA model, using queuing variables, in order to demonstrate its usefulness in the evaluation of the current patient flow system. The objectives of the current study are: (i) to identify excessive varying wait times of patients, (ii) to identify relevant queuing variables affecting the waiting times which need to be included in the DEA model, and (iii) to assess the usefulness of DEA Modeling in analyzing a queuing system.

The remainder of this paper is structured into further four sections. The second section highlights some of the DEA applications in health. The third section describes the development of the DEA model. We have also demonstrated applicability of the proposed model in application of waiting time of patient follows. The fourth section explains the significance of these results for improving the current system including some propositions for the betterment of the patient flow system. The final section explores the opportunities for future research. 


\section{Data Envelopment Analysis}

\subsection{DEA Applications in Healthcare}

Since the early 1980s, efficiency analysis has been used to measure and analyse the productive performance of health care services (Hollingsworth 2008). Efficiency measurement represents the first step towards the evaluation of a coordinated health care system, and constitutes one of the basic means of audit for the rational distribution of human and economic resources (Ramanathan 2005). One of the most-widely used techniques in this respect is DEA. Nunamaker (1983) and Sherman (1984) were the first published papers which applied DEA in the field of healthcare. Since then, DEA has enjoyed numerous healthcare applications. Some studies have provided a comprehensive review of DEA applications in health (Liu et al., 2013b; Hollingsworth 2012; Hollingsworth 2008; Worthington 2004).

The DEA literature consists of efficiency measurement of different units of analysis within the healthcare sector. These include private versus public hospitals (Chang et al., 2004; Jehu-Appiah et al., 2015), primary healthcare centres in urban versus rural municipalities (Ramirez-Valdivia et al., 2012), acute care hospitals (Hollingsworth and Parkin 1995; Ersoy et al., 1997; Puig-Junoy 2000; Tsai and Molinero 2002), family health services authorities (FHSAs) (Salinez-Jaminez and Smith 1996) and district health authorities (DHAs) (Thanassoulis et al., 1996). A few other studies were concerned with the efficiency comparison of physicians (Chilingerian and Sherman 1997; Wagner et al., 2003), nurses (Osman et al., 2011), ambulatory surgery centers (ASCs) (Lewis et al., 2011), immunization activities in primary care practices (Rouse et al., 2011) and dialysis facilities (Flokou et al., 2011). None of these studies comprise of efficiency analysis of the patient flow system in a hospital. The objective of the current study is to assess the queuing system in a busy public hospital of a developing country using DEA, demonstrating its effectiveness in the assessment of a patient flow system.

\subsection{Theoretical Background and DEA Framework}

DEA is a non-parametric efficiency measurement technique which does not require any a priori assumptions of the functional form of a production function. It is used to assess the efficiency levels of different units of analysis, known as decision-making units (DMUs), using multiple inputs and outputs. The DEA framework was first developed by Charnes et al., (1978), also known as CCR Model. Later on, the traditional DEA model was extended by Banker et al., (1984), most popularly known as the BCC Model.

The basic concept of DEA comes from the production frontier approach as discussed by Farrell (1957). DEA allows for the construction of an 'efficient frontier' formed by a set of DMUs that demonstrate best practices. It then allocates the efficiency level to all units based on their distances from the efficient frontier. Units which lie on the frontier are said to be $100 \%$ efficient, while others which are away from the frontier are inefficient, with efficiency scores below 100\%. DEA identifies a 
reference set for each inefficient DMU, which comprises of corresponding efficient DMUs that can be used as benchmarks for improvement. DEA also allows for calculation of target values of inputs and outputs for a particular inefficient DMU, which shows the amount required for each of these variables to increase the efficiency level to 100\% (Liu et al., 2013a; Lee and Kim 2014).

A DEA model could either be input-oriented or output-oriented. Basically, an input-oriented model is concerned with minimizing the quantity of inputs given that the same amount of outputs is produced. An output-oriented model focuses on maximizing the quantity of output produced subject to the condition that the amount of inputs remains unchanged (Charnes et al., 1978; Banker et al., 1984).

A case of two-input and one-output model can be represented graphically as shown in Figure 1. There are four DMUs, $A_{1}, A_{2}, A_{3}$ and $A_{4}$, each producing the same amount of output, $O_{1}$ while using different combinations of inputs, $I_{1}$ and $I_{2}$. This is an 'input-oriented' model as the objective is to reduce the number of inputs given the same level of output. The line SS' is the estimated efficient frontier for the four DMUs.

Three of the DMUs, $\mathrm{A}_{1}, \mathrm{~A}_{3}$ and $\mathrm{A}_{4}$ are $100 \%$ efficient as they are lying on the frontier. However, $\mathrm{A}_{2}$ is inefficient as it consumes more resources as compared to other DMUs. $A_{2}$ can become $100 \%$ efficient if it operates as point $\mathrm{M}$ (at the efficiency frontier). Therefore, the efficiency of $\mathrm{A}_{2}$ at this point is $\mathrm{OM} / \mathrm{OA}_{2}$. This type of efficiency is known as the technical efficiency of a unit. $\mathrm{A}_{1}$ and $\mathrm{A}_{3}$ are the 'efficient peers' of $A_{2}$, that is, the units which act as a source of guidance for the inefficient unit $A_{2}$ to improve its operational efficiency. The DMUs representing the efficient peers are the ones which have the most closely related input/output combination to that of the particular inefficient unit.

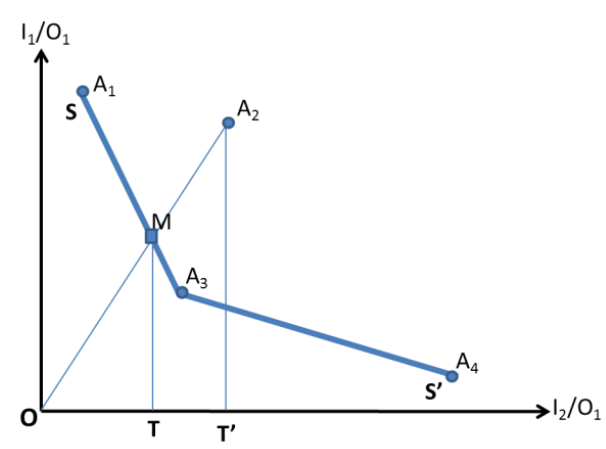

Figure 1: Measuring efficiency graphically for the input-oriented DEA model

However, when the number of inputs and outputs increase, the model becomes more complicated and is solved by constructing a linear programming model.

\subsection{Mathematical Representation of DEA}

In general terms, the efficiency is defined as the ratio of output to input. Mathematically, the technical efficiency in DEA is defined as the ratio of the weighted sum of outputs to the weighted sum of 
inputs. Assuming there are ' $\mathrm{n}$ ' DMUs, then for any $\mathrm{DMU}_{0}$ the efficiency score which lies between 0 and $1(0$ to $100 \%)$ is defined as $0 \leq \frac{\sum_{r=1}^{s} u_{r} y_{r 0}}{\sum_{i=1}^{m} v_{i} x_{i 0}} \leq 1$ where;

s: total number of outputs

m: total number of inputs

$\mathbf{y}_{\mathrm{rj}}$ : amount of ' $r$ 'th' outputused by DMU $\mathrm{D}_{\mathrm{j}}$ where $r=1, \ldots, s$ and $j=1, \ldots, n$

$\mathbf{x}_{\mathrm{ij}}$ : amount of ' $i^{t h}$ ' input used by $\mathrm{DMU}_{\mathrm{j}}$ where $i=1, \ldots m$ and $j=1, \ldots, n$

$\mathbf{y}_{\mathbf{r} 0}$ : amount of output $r$ used by the DMU under assessment

xio: amount of input $\mathrm{i}$ used by the DMU under assessment

ur: weight assigned by DEA to output $r$

$\mathbf{v}_{\mathbf{i}}$ : weight assigned by DEA to input $\mathrm{i}$

Using the above concept Charnes et al., (1978) transferred this to the following linear programming for measuring efficency of $\mathrm{DMU}_{0}$.

In this mathematical programming, the objective is to obtain the weights $\mathrm{u}_{\mathrm{r}}$ and $\mathrm{v}_{\mathrm{i}}$ which maximize this ratio of weighted outputs to weighted inputs for $\mathrm{DMU}_{0}$. The basic idea behind weight allocation is that each unit might value inputs and outputs differently and therefore adopt different weights. Hence, each unit should be allowed to adopt the most favourable weights in order to maximize its efficiency ratio. A dual to model 1 is presented in Model 2.

\section{Model 1: CCR Multiplier Model}

Maximize $\mathrm{h}_{0}=\sum_{\mathrm{r}=1}^{\mathrm{s}} \mathrm{u}_{\mathrm{r}} \mathrm{y}_{\mathrm{r} 0}$

subject to:

$\sum_{\mathrm{i}=1}^{\mathrm{m}} \mathrm{v}_{\mathrm{i}} \mathrm{x}_{\mathrm{i} 0}=1$

$\sum_{\mathrm{r}=1}^{\mathrm{s}} \mathrm{u}_{\mathrm{r}} \mathrm{y}_{\mathrm{rj}}-\sum_{\mathrm{i}=1}^{\mathrm{m}} \mathrm{v}_{\mathrm{i}} \mathrm{x}_{\mathrm{ij}} \leq 0 ; \forall j$

$\mathrm{u}_{\mathrm{r}}, \mathrm{v}_{\mathrm{i}} \geq 0 \quad ; \forall i, r$

\section{Model 2: CCR Envelopment Model}

Minimize $\mathrm{Z}-\left(\sum_{r=1}^{s} \mathrm{~s}_{\mathrm{r}}^{+}+\sum_{i=1}^{m} \mathrm{~s}_{\mathrm{i}}^{-}\right)$

subject to:

$\sum_{\mathrm{j}=1}^{\mathrm{n}} \lambda_{\mathrm{j}} \mathrm{y}_{\mathrm{rj}}-\mathrm{s}_{\mathrm{r}}^{+}=\mathrm{y}_{\mathrm{r} 0} ; \forall r$

$\sum_{\mathrm{j}=1}^{\mathrm{n}} \lambda_{\mathrm{j}} \mathrm{x}_{\mathrm{ij}}-\mathrm{Zx}_{\mathrm{i} 0}+\mathrm{s}_{\mathrm{i}}^{-}=0 ; \forall i$

$\lambda_{\mathrm{j}}, \mathrm{s}_{\mathrm{r}}^{+}, \mathrm{s}_{\mathrm{i}}^{-} \geq 0 ; \forall j, r, i$

In Model 2, if the value of $h_{0}$ is 1 , and all slacks are zero, then this $\mathrm{DMU}_{0}$ is efficient relative to other DMUs in the set. In case $h_{0}$ is less than 1 , this unit is inefficient when compared with others. The original CCR Model operated under the assumption of constant return to scale (CRS). This traditional model was later extended by Banker et al., (1984) to incorporate variable return to scale (VRS) by adding the following additional constraint in Model (2):

$\sum_{\mathrm{j}=1}^{\mathrm{n}} \lambda_{\mathrm{j}}=1$

This new constraint was introduced in order to determine whether a firm is operating in the region of increasing, constant or decreasing returns to scale (in multiple input and multiple output situation) utilizing the concept of Sheppard's distance function as shown by Banker et al., (1984) (Emrouznejad and Cabanda 2014). 


\section{A DEA Model for the Assessment of a Queuing System}

\subsection{Patient pathway considered for the current study}

The Outpatients' department (OPD)of one of the typical public hospitals in Pakistan was observed to identify the major waiting times, where all patients are walk-in. There are different pathways that a patient can follow from the entry till exit. One of them (as shown in Figure 2) is that a patient arrives at the OPD in order to consult with the General Duty Medical Officer (GDMO) and after consultation proceeds to the Pharmacy. In this case, the patients have to wait at two stages, the OPD and Pharmacy. The observations at these two stages showed that the patients have to suffer extensive waiting times. Therefore, there is a dire need to assess the efficiency of this patient pathway mainly in terms of waiting times of patients, and also identify other factors that affect these waits The DEA modelling was utilized in order to evaluate the current queuing system and to provide guidelines for improvement.

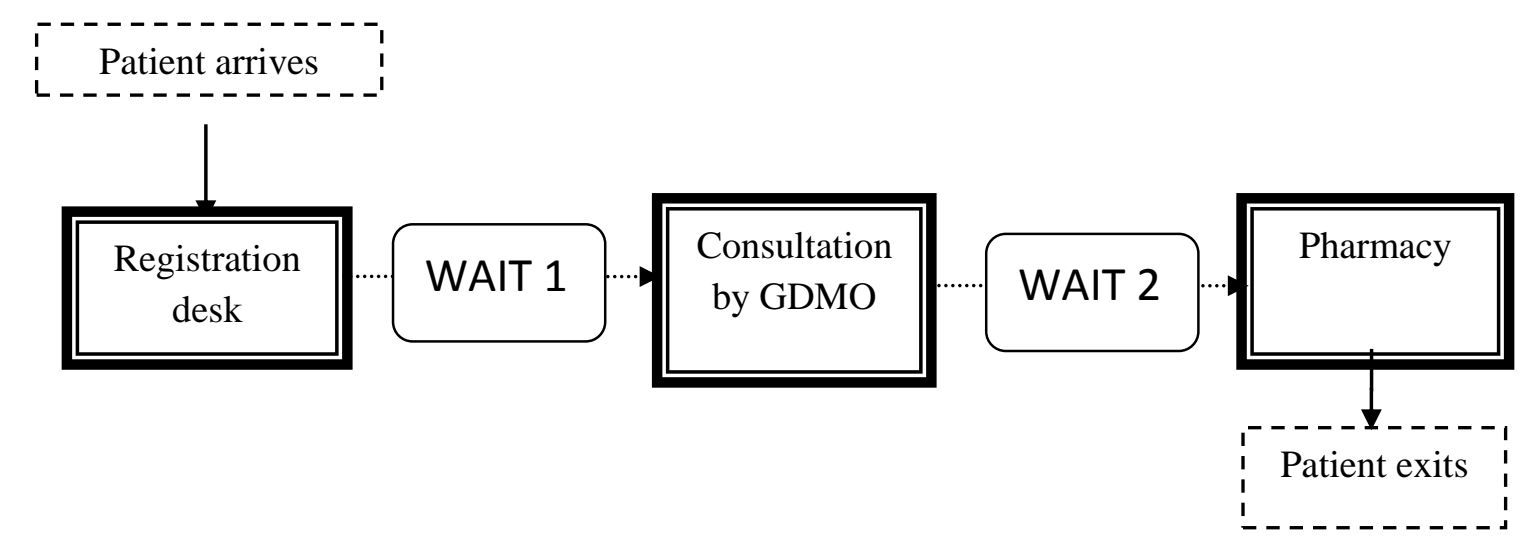

Figure 2: Patient flow system representing two types of waiting times

\subsection{Selection of input and output variables in the DEA model}

Selection of relevant inputs and outputs is a common issue in DEA (Harrison et al., 2004). Inclusion of inputs and outputs does not only affect the results but also the ability of a particular methodology to provide useful information (Hollingsworth and Parkin 1995). However, the input and output variables included in the DEA model and their interpretation depend on the nature of the problem under consideration. Most of the DEA studies have been conducted in order to compare the efficiency of hospitals. For this purpose, these studies have considered various inputs and outputs. Table 1 shows the most commonly used inputs and outputs in previous DEA studies when comparing hospitals.

Table 1: Most Common Health-related inputs and outputs in DEA

\begin{tabular}{l|l}
\hline Output variables & Input variables \\
\hline Number of Outpatient visits & Number of beds \\
(Bwana 2015; Flokou et al., 2011; Masiye et al., 2006; & (Bwana 2015; Kose et al., 2014, Al-Shammari 1999; Akazili \\
Ramanathan 2005; Zuckerman et al., 1994) & $\begin{array}{l}\text { et al., 2008; Harrison et al., 2004; Puig-Junoy 2000; Weng } \\
\text { et al., 2009; Magnussen 1996) }\end{array}$ \\
\hline
\end{tabular}




\begin{tabular}{|c|c|}
\hline $\begin{array}{l}\text { Number of Inpatient visits } \\
\text { (Chuang et al., 2011; Butler and Li 2005; Tsai and } \\
\text { Molinero 2002; Zere et al., 2001; Banker et al., } 1986 \text {; } \\
\text { Kawaguchi et al., 2014) }\end{array}$ & $\begin{array}{l}\text { Number of doctors } \\
\text { (Grosskopf and Valdmanis 1987; Kirigia et al., 2008; } \\
\text { Chang et al., 2004; Huang et al., 1989; Prior 2006; Kose et } \\
\text { al., 2014; Dotoli et al., 2015) }\end{array}$ \\
\hline $\begin{array}{l}\text { Number of major and minor surgeries } \\
\text { (Al-Shammari 1999; Chang et al., } 2004 \text {; Puig-Junoy } \\
2000 \text {; Gerdtham et al., } 1999 \text {; Dotoli et al., 2015) }\end{array}$ & $\begin{array}{l}\text { Number of nurses } \\
\text { (Chuang et al., 2011; Masiye et al., 2006; Hollingsworth } \\
\text { and Parkin 1997; Byrnes and Valdmanis 1993; Kawaguchi } \\
\text { et al., 2014) }\end{array}$ \\
\hline $\begin{array}{l}\text { Number of emergency visits } \\
\text { (Butler and Li } 2005 \text { Grosskopf and Valdmanis 1987; Linna } \\
\text { 1998; Kang et al., 2014) }\end{array}$ & $\begin{array}{l}\text { Other medical and non-medical staff members } \\
\text { (Dotoli et al., 2015; Kirigia et al., 2004; Huang et al., 1989; } \\
\text { Hollingsworth and Parkin 1995; Ramanathan 2005; } \\
\text { Valdmanis 1992) }\end{array}$ \\
\hline $\begin{array}{l}\text { Number of discharges } \\
\text { (Blank and Van Hulst 2011; Puig-Junoy 2000; } \\
\text { Hollingsworth and Parkin 1997; Kose et al., 2014; Dotoli } \\
\text { et al., 2015) }\end{array}$ & $\begin{array}{l}\text { Costs: } \\
\text { - Expenditures on supplies } \\
\text { (Akazili et al., 2008; Kirigia et al., 2008; Kawaguchi et al., } \\
\text { 2014) } \\
\text { - Total inpatient costs } \\
\text { (Nunamaker 1983) } \\
\text { - Operating expenses } \\
\text { (Harrison et al., 2004; Tsai and Molinero 2002; Zere et al., } \\
\text { 2001; Byrnes and Valdmanis 1993) }\end{array}$ \\
\hline
\end{tabular}

Considering the health-related queue management studies, different researchers have used a number of variables and parameters to assess and improve a particular queuing system. Table 2 shows the most commonly used variables for queuing analysis in healthcare.

Table 2: Most Commonly Used Queuing Variables Used in Healthcare Studies

\begin{tabular}{|c|c|}
\hline Queuing variables & Definition \\
\hline Waiting time & $\begin{array}{l}\text { - Difference between arrival time and the time consultation/service begins } \\
\text { (Adeleke et al., 2008; Gul and Guneri 2015; Sorup et al., 2015) } \\
\text { - Difference between arrival time and appointment time } \\
\text { (Harper and Gamlin 2003) } \\
\text { - Waiting time for early or late arrival for appointment } \\
\text { (O'Keefe (1998); Zhu et al., 2012) } \\
\text { - Response time } \\
\text { (Aboueljinane et al., 2013) }\end{array}$ \\
\hline Service Time & $\begin{array}{l}\text { - Difference between the time when consultation started and when it ended } \\
\text { (Welch 1964; Hill-Smith 1989; Brahimi and Worthington 1991; Adeleke et al 2009; } \\
\text { Harper and Gamlin 2003; Khori et al., 2012; Mankowska et al., 2014) }\end{array}$ \\
\hline Number of Resources & $\begin{array}{l}\text { - The number of resources available upon arrival of patients mainly including personnel } \\
\text { (doctors/nurses/other staff) and beds } \\
\text { (Lane et al., 2000;Griffiths et al., 2005; Gunal 2012; Mankowska et al., 2014; Gul and } \\
\text { Guneri 2015) }\end{array}$ \\
\hline No-shows & $\begin{array}{l}\text { - When patients do not arrive for their appointments } \\
\text { (Hassin and Mendel 2008; Klassen and Yoogalingham 2009; Feldman et al., 2014) }\end{array}$ \\
\hline Average Queue length & $\begin{array}{l}\text { - The length of the queue at a particular time } \\
\text { (Huarng et al 1996; Cote 1999; Silvester et al., 2004; Gul and Guneri 2015) }\end{array}$ \\
\hline Idle time of doctors & $\begin{array}{l}\text { - The amount of time that the doctors are not busy } \\
\text { (Fetter and Thompson 1966; Klassen and Rohlder 1996; Cayirli et al., 2008) }\end{array}$ \\
\hline
\end{tabular}

Taking into account the variables considered by the DEA and queue management studies, and the objective of the current study which is to assess the patient flow system using DEA, the inputs and outputs for the proposed DEA-queuing Model are shown in Table 4. Since the objective is to improve the efficiency of the queue system, an input-oriented DEA model will be run in order to reduce the 
waiting time of patients as well as other inputs, while keeping the level of availability of the doctors at the same level. The proposed Model is described in the following sections.

Table 3: Inputs and outputs for the proposed DEA-queuing Model

\begin{tabular}{ll}
\hline Inputs & Outputs \\
\hline Waiting to be seen by GDMO (WAIT1) & Number of GDMOs (NuGDMO) \\
Waiting at the Pharmacy (WAIT2) & Number of Pharmacists (NuPHAR) \\
Length of Queue for WAIT1 (LEQ1) & \\
Length of Queue for WAIT2 (LEQ2) & \\
Consultation Time (CONS) & \\
Service Time at the Pharmacy (SERT) & \\
\hline
\end{tabular}

\subsection{1) Assessment of the Queuing System Using Patient level Data in the DEA Model}

In order to assess the queuing process, it is extremely important to look at the input and output of each individual patient. The DEA modelling provides detailed analysis for each and every unit of analysis in the dataset. This sort of in-depth analysis is not provided in any of the other OR techniques. Also, it is extremely important to include patients as the 'units of analysis' in the DEA model to analyse the queuing process. The utilization of patient level data is significant as it allows to pinpoint the extreme wait times experienced by patients and the reasons behind them. Usually with other DEA studies, the whole organization is considered as a DMU (for example, hospitals, banks, schools and so on), where one is compared with another. However, the objective of the current study is to evaluate the queuing process in 'one' large public hospital. Therefore, data regarding each individual patient will be gathered and a comparison among them will assist in evaluating the overall queue system.

This queue assessment represents a distinctive application of DEA modelling, moving away from its traditional usage in analysing a pure 'production' process, where inputs are turned into outputs. The current study aims to demonstrate that DEA has other applications in addition to its 'traditional' use.

\subsection{2) Outputs of the DEA Model: Number of GDMOs and Pharmacists}

It can be observed from Table 1 that none of the health-related DEA studies have used any outputs which are related to the queuing of patients. Most of the variables included in Table 1 cannot be used in the current study since the main objective in these studies is to assess the efficiency level of each 'hospital'; therefore, the inputs and outputs represent aggregate values recorded for every individual DMU (hospital). For instance, 'number of doctors' represents the total number of doctors working at the hospital. However, in the current study, the goal is to identify the efficiency of the current patient flow system in the Outpatients' department within one hospital. Therefore, the value of the number of GDMOs and Pharmacists will be recorded at the time each individual patient arrived at the outpatients' department and pharmacy respectively. 
Both these variables will be included in the model as outputs. It can be observed from Table 1 that in DEA studies, staff members, either medical or non-medical, are one of the most widely used inputs. In these studies, the number of personnel (doctors, nurses etc) is included as an input with the objective to minimize the number of staff in order assess and improve the efficiency of a hospital. However, the main goal of the current study is to evaluate and reduce the excessive waiting time of patients. Therefore, the objective is to identify that to what extent does the wait time needs to be reduced given the fixed number of doctors working at that particular time when a patient arrived. Therefore, from this perspective, the number of GDMOs and pharmacists are included as outputs in order to analyse the required reduction in excessive wait times..

Considering these variables as outputs will assist the management in appropriate staff allocation. This information can be used by managers to ensure that an adequate number of staff is working when there are more patients in order to minimize the waiting time.

\subsubsection{Inputs of the DEA Model}

\section{Waiting to be seen by the GDMO and at the Pharmacy}

Almost all prior queuing studies are associated with improving an existing appointment system. Therefore, waiting times are mostly defined with respect to the appointment times as shown in Table 2. As indicated before, the goal of the present study is to formulate a DEA model in a public hospital of a third-world country where there are no appointments. Therefore, the waiting times of 'walk-in' are described differently as compared to previous works. The waiting time to be examined by the GDMO (WAIT 1) is the difference between the time when a patient enters the consultation room and the time of entry at the reception of the Outpatients' Department. The waiting time at the Pharmacy (WAIT 2) is considered as the difference between the time when a patient arrives at one of the pharmacy counters to obtain service and the time of entry at the pharmacy reception.

The wait time of each patient will be recorded to determine the efficiency level of the pathway followed by each individual patient. Both waiting times are included as inputs in the model. Due to lack of resources and overloading of patients in developed nations, there are excessive wait times of the patients. Hence, the current DEA model aims to identify the excessive wait times, which might vary from one patient to another, with the objective of minimizing them. This analysis will assist in identifying high wait times experienced by patients and the factors affecting them, so that appropriate measures can be taken to improve the existing queuing situation.

Also, the waiting time of patients is strongly related to the number of doctors available. Table 3 indicates that waiting times and number of personnel have been considered jointly in most studies to assess the queuing situation. In most of the previous works, the objective is to 'minimize' the number of doctors and observe its effect on the wait times of patients. However, in the current study, the 
objective is different in that the relationship of wait time and the number of doctors/pharmacists available is expressed such that wait time is an input and the number of personnel is an output. The idea is to allow for the minimization of wait time given the current availability of doctors and pharmacists, so that proper measures for staff allocation can be undertaken to control the queue problem

\section{Length of Queue for WAIT 1 and WAIT 2}

As indicated by Table 2, average queue length has been considered as a significant variable for analysing a particular queuing system. In the current study, queue length is defined as the number of people already waiting when a patient joins the queue. The length of queue is an indicator of an overload in a particular queue system. If more patients are waiting at the time of arrival of a particular patient, the longer will be the queue, hence leading to excessive wait time of the current patient. Therefore, this variable has been included in the DEA model, to observe the extent of overload in the queue system when a patient arrived and its effect on the wait time.

Moreover, the length of queue indicates the level of efficiency of the current system, by highlighting the lack of availability of adequate staff members. Therefore, the queue lengths at both stages, consultation with the GDMO (LEQ1) and pharmacy (LEQ2), will be included as inputs with number of personnel as outputs.

\section{Consultation time and service time at the Pharmacy}

One of the most widely used criteria for queuing analysis is the service time as specified in Table 2. In the current study, consultation time has been included in the DEA model as a proxy to service time for WAIT 1 and WAIT 2. It is assumed that the patients arriving at the Outpatients' department have similar medical issues. Hence the actual consultation and diagnosis are similar for all patients.

The consultation in the public hospitals comprises of a number of miscellaneous tasks in addition to the 'actual' consultation. These tasks might include data entry (such as demographic details of patients), carrying out routine activities (such as measuring blood pressure, pulse rate, temperature etc), preparing prescriptions for medicines and some others. These additional tasks take a considerable amount of time during the actual consultation and as a result, increases the waiting time of the subsequent patients. Therefore, the consultation time has been included as an input in the DEA model, in order to pinpoint high consultation times and its effect on the wait time and queue size. The idea is to bring to the attention to the management as to the causes of high consultation so that appropriate measures can be undertaken.

At the Pharmacy, the service time should be minimal since the patients just need to collect their medicines. Excessive time for the distribution of medicines is a sign of inefficiency and requires some intervention. There might be a number of reasons for delayed response at the Pharmacy such as 
understanding the given prescriptions, bringing medicines from different sections of the store and some others. Therefore, service time at Pharmacy is included as an input since the objective is to identify the causes of delayed response at the pharmacy and minimize the wait by taking appropriate actions.

Consultation time and service time at the pharmacy are strongly related to the number of personnel available. This evaluation allows for highlighting the issue that increased service times coupled with inadequate staff members at both stages increase the wait times of subsequent patients, hence reducing the efficiency of the system. Therefore, these are included as inputs in this model with number of servers as outputs.

\section{Consultation time included as an input with a pre-specified priority}

A number of extensions of the traditional DEA model has been proposed in the DEA literature, and one of them is the inclusion of preference information of the decision-makers. The DEA literature shows that several attempts have been made to incorporate preference information, mainly with the objective of target setting (Halme et al., 1999). Golany (1988) proposed the idea that the preference information should be considered in order to allow for selecting the most appropriate efficient output target among different alternatives. Thanassoulis and Dyson (1992) have developed models for target setting which include varying preferences over improvement to the levels of individual inputs and outputs. Zhu (1996) constructed weighted non-radial DEA models that incorporate preference structures, in order to acquire efficient targets and corresponding efficiency scores for each DMU. Athanassopoulos et al., (1999) developed a scenario-based process for estimating targets using DEA which is in line with the decision makers' set preferences for the strategies to be adopted.

The traditional DEA assumes that all inputs and outputs are equally important. However, in few cases, some variables might be preferred over others (Halme et al., 1999). Thanassoulis and Dunstan (1994) applied the target setting models with different preferences in the education sector where the mean GCSE score output had a higher priority than the output of the percentage of pupils who got a placement on leaving school. In a study on the comparison of suppliers' performance, Liu et al., (2000) considered distance and supply variety as exogenously fixed input variables. Martic and Savic (2001) provided a comparison of different regions in Serbia with respect to social-economic development, considering the input variables of arable area and population as exogenously fixed. Thanassoulis et al., (1995) conducted a study on the provision of prenatal care in England, and considered five output quality measures as exogenously fixed. A modified DEA model with weight restrictions was adopted to reflect preferences over these output quality measures. In the present case scenario, consultation time is added in the model with a pre-specified priority. 
There are negligible studies in health which incorporate preference information. In the field of healthcare, the inclusion of this preference information is crucial, since some factors indicate the 'quality' of health services provided and affects patient satisfaction. Therefore, these health variables should only be minimized up to a certain level. Hence, by incorporating priorities for some health variables, DEA analysis provides targets which are achievable and realistic, and reflect the preferences of the policy makers. In the current study, the consultation time is considered with a priority. Consultation with a doctor is the most important service provided by a hospital which reflects the level of patient care and is an indicator of patient satisfaction. Therefore, it should not be allowed to decrease below a 'certain' level as it might reflect badly on the quality of service provided. However, considering other pre and post diagnosis activities as part of the consultation, the time can be reduced such that it only consists of the 'actual' consultation. The other activities can take place either before or after the consultation. This will minimize the overall consultation time and reduce the wait time of subsequent patients.

After discussion with the hospital administrators in the index hospital and considering their expert opinion, it was decided that the level of Consultation time should not be allowed to decrease below $50 \%$. The administrators were of the opinion that although there are other tasks carried out during the 'actual' consultation, but still the total Consultation time should not be allowed to reduce for more than $50 \%$ due to its significant nature in the provision of health services.

The inclusion of preference information highlights one of the key advantages of DEA modelling. DEA has the ability to incorporate variables with a certain priority, leading to a better representation of a real-life scenario. Furthermore, the priority level for a certain variable can be changed in order to reflect the preference of administrators.

Therefore, a modified DEA model is shown below:

\section{Model 3: Priority setting in the CCR model}

\section{Max q}

subject to:

$$
\begin{array}{lc}
\sum_{\mathrm{j}=1}^{\mathrm{n}} \mathrm{x}_{\mathrm{ij}} \lambda_{\mathrm{j}}+\mathrm{s}_{\mathrm{i}}^{-}=x_{i j_{0}}\left(1-\mathrm{w}_{\mathrm{i}} \mathrm{q}\right) & \mathrm{i}=1, \ldots, \mathrm{m} \\
\sum_{\mathrm{j}=1}^{\mathrm{n}} \lambda_{\mathrm{j}} \mathrm{y}_{\mathrm{rj}}-\mathrm{s}_{\mathrm{r}}^{+}=\mathrm{y}_{\mathrm{r} j_{0}}\left(1+\mathrm{w}_{\mathrm{r}} \mathrm{q}\right) & \mathrm{r}=1, \ldots, \mathrm{s}
\end{array}
$$

Where:

$\mathrm{x}_{\mathrm{ij}}$ and $\mathrm{y}_{\mathrm{rj}}$ are the $\mathrm{i}^{\text {th }}$ input and the $\mathrm{r}^{\text {th }}$ output level at $\mathrm{DMU}_{\mathrm{j}}$,

$\mathrm{W}_{\mathrm{i}}$ and $\mathrm{w}_{\mathrm{r}}$ are the specified priorites,

$\mathrm{j}_{0}$ is the DMU being assessed. 
In order to estimate the radial efficiency of $\mathrm{DMU}_{0}$ under input minimisation we set $\mathrm{w}_{\mathrm{i}}=100 \% ; \quad \forall i \&$ $\mathrm{w}_{\mathrm{r}}=0 ; \forall r$. (This conditions are reversed in case of an output maximisation problem;. i.e. $\mathrm{w}_{\mathrm{i}}=0 ; \forall i \& \mathrm{w}_{\mathrm{r}}=$ $100 \% ; \forall r)$

Now, for the current study, an input-oriented DEA model will be utilized (see Section 4 for details), and only consultation time is added as a priority input variable (with a priority of 50\%). Therefore, the above priorities will be re-defined as follows:

$\mathrm{w}_{\mathrm{i}}=100 \%$ for $\mathrm{i}=$ WAIT 1 , WAIT 2, LEQ 1, LEQ 2 and SERT

$\mathrm{w}_{\mathrm{i}}=50 \%$ for $\mathrm{i}=\mathrm{CONS}$

$\mathrm{w}_{\mathrm{r}}=0 \quad \forall r$

Model (3) is solved in two stage, where in the second stage we maximise the sum of slacks, as follows, over the same constraints.

$\operatorname{Max} \sum_{r=1}^{s} \mathrm{~s}_{\mathrm{r}}^{+} \mathrm{F}_{\mathrm{r}}^{+}+\sum_{i=1}^{m} \mathrm{~s}_{\mathrm{i}}^{-} \mathrm{F}_{\mathrm{i}}^{-}$

Where $\mathrm{F}_{\mathrm{i}}^{-}$and $\mathrm{F}_{\mathrm{r}}^{+}$are the specified priorities .

\section{Results and discussion}

The results obtained from the DEA analysis are expected to highlight the excessive varying waiting times of patients and the factors affecting them in the present queuing system.

For this purpose, some preliminary observations regarding the arrival pattern of patients and the overall queue system were conducted in the busiest outpatients' department of a large public hospital in Pakistan. These observations were conducted for one full week during different times of the day. These initial observations were then used to simulate a dataset for 200 patients, which represents the patient flow in a busy outpatients' department of a public hospital in a developing country in one day. This simulated dataset was then utilized for DEA analysis. In order to conduct DEA analysis, PIMDEA software ${ }^{2}$ (Version 3.2) was employed

Figure 3 demonstrates that 35 units (out of 200) are 100\% efficient whereas the remaining 165 units are inefficient. However, units with different 'inefficiency' levels can have varying input/output characteristics. Therefore, to develop a better understanding of the DEA results, the inefficiency levels are further divided into different ranges.

ww.DEAsoftware.co.uk 


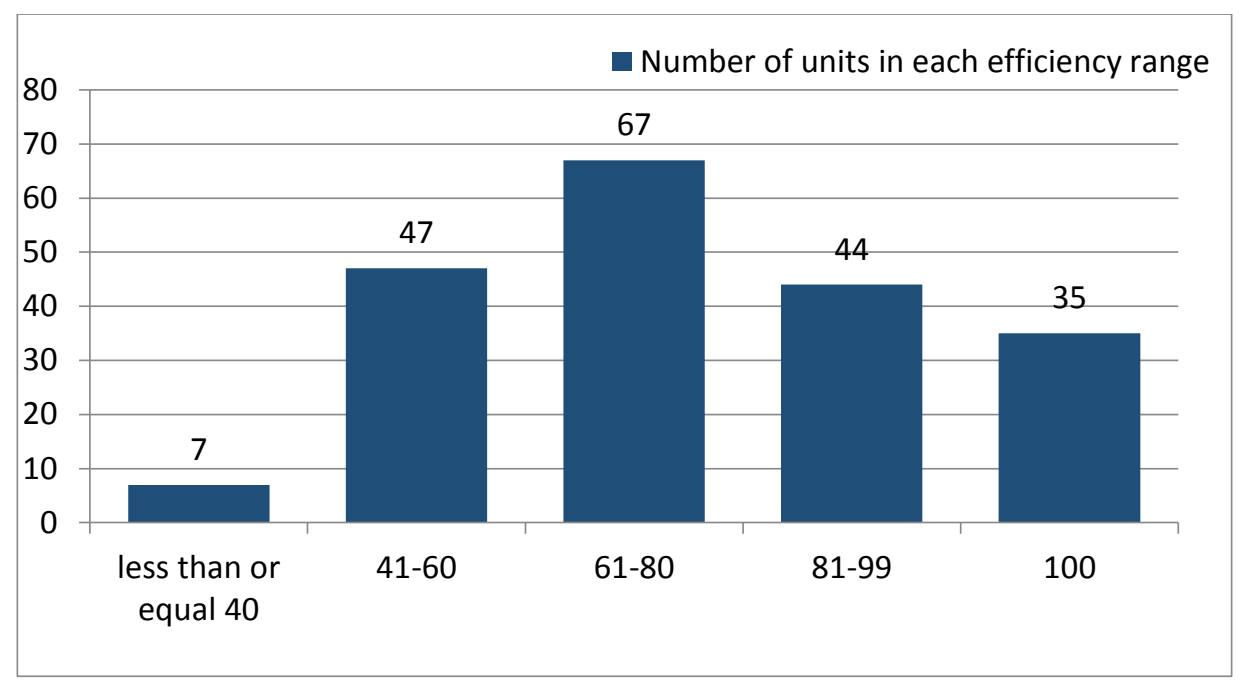

Figure 3: Number of units lying in different efficiency ranges

To show the usefulness of the proposed approach, summary results of some patientsare shown in Table 4, representing the actual and target values of the inputs. The target values indicate the amount by which these inputs can be decreased in order to increase the efficiency level to $100 \%$. This information is very useful since it provides a guideline to the administrators to take appropriate measures for reducing the waiting time in this busy hospital.

Table 4: DEA results for selected patients in an input-oriented model

\begin{tabular}{|c|c|c|c|c|c|c|c|c|c|c|c|c|c|}
\hline \multirow{2}{*}{$\begin{array}{l}\text { Patient } \\
\text { No }\end{array}$} & \multirow{2}{*}{$\begin{array}{c}\text { Eff } \\
(\%)\end{array}$} & \multicolumn{2}{|c|}{ CONS } & \multicolumn{2}{|c|}{ LEQ1 } & \multicolumn{2}{|c|}{ WAIT1 } & \multicolumn{2}{|c|}{ LEQ2 } & \multicolumn{2}{|c|}{ WAIT 2} & \multicolumn{2}{|c|}{ SERT } \\
\hline & & Actual & Target & Actual & Target & Actual & Target & Actual & Target & Actual & Target & Actual & Target \\
\hline $\mathrm{P} 1$ & 71 & 20 & 17 & 11 & 8 & 177 & 103 & 29 & 21 & 84 & 60 & 5 & 4 \\
\hline P5 & 100 & 43 & 43 & 9 & 9 & 82 & 82 & 22 & 22 & 38 & 38 & 5 & 5 \\
\hline P17 & 86 & 40 & 26 & 11 & 9 & 96 & 66 & 16 & 14 & 66 & 56 & 7 & 4 \\
\hline P32 & 44 & 24 & 13 & 8 & 4 & 71 & 31 & 18 & 8 & 103 & 45 & 5 & 2 \\
\hline P38 & 58 & 23 & 18 & 13 & 6 & 117 & 44 & 17 & 10 & 134 & 43 & 4 & 2 \\
\hline P56 & 23 & 21 & 11 & 13 & 3 & 144 & 33 & 21 & 5 & 224 & 51 & 7 & 2 \\
\hline P64 & 53 & 16 & 12 & 8 & 4 & 114 & 51 & 24 & 13 & 170 & 87 & 5 & 3 \\
\hline P75 & 100 & 32 & 32 & 10 & 10 & 64 & 64 & 14 & 14 & 66 & 66 & 2 & 2 \\
\hline P81 & 40 & 39 & 14 & 10 & 4 & 59 & 23 & 27 & 9 & 138 & 55 & 5 & 2 \\
\hline P87 & 89 & 32 & 30 & 11 & 9 & 63 & 56 & 20 & 14 & 112 & 73 & 4 & 4 \\
\hline P95 & 100 & 29 & 29 & 8 & 8 & 42 & 42 & 11 & 11 & 84 & 84 & 7 & 7 \\
\hline P111 & 39 & 37 & 18 & 13 & 5 & 132 & 44 & 14 & 5 & 170 & 66 & 5 & 2 \\
\hline P120 & 91 & 13 & 12 & 10 & 9 & 135 & 63 & 23 & 19 & 102 & 93 & 4 & 4 \\
\hline $\mathrm{P} 183$ & 70 & 15 & 13 & 5 & 4 & 105 & 74 & 29 & 17 & 136 & 69 & 5 & 3 \\
\hline P194 & 67 & 39 & 21 & 8 & 5 & 174 & 60 & 16 & 11 & 167 & 112 & 4 & 3 \\
\hline
\end{tabular}

For instance, consider P5, although Wait 1 and Queue length 2 are higher, but Consultation time, Queue length 1 and Wait 2 are lower, which leads to P5 being 100\% efficient. For P95, Wait 2 has slightly higher values with lower values for all other inputs. P75 has the lowest values for all inputs among the three efficient units. Based on these results, it can be said that Consultation time of around 30 minutes, Queue length 1 and 2 of around 10 patients and Wait 1 and 2 of around an hour represents an efficient patient flow system. However, slightly higher values of some the inputs while reduced values of others can compensate each and result in an overall efficient unit. 
Considering the inefficient units, P56 is the most inefficient among all with an efficiency level of just $23 \%$. One of the reasons is the extremely high value of Wait 2 which is nearly 4 hours. Also, Wait 1 is around 2 hours. Hence, although consultation time and queue length 1 are not that high but the target values show that they should be reduced to 11 and 3; respectively. In order to balance high waiting times, other inputs should be reduced considerably with the purpose of making the process efficient. For P81, Wait 2 is over 2 hours; hence although Wait 1 is almost an hour, it needs to be reduced further in order to increase the efficiency level of the unit. Also, the consultation time and queue length 1 and 2 need to be minimized. Similar observations can be made about other patients which have efficiency levels less than or around 50\% such as P32, P38, P64, and P111. The service time for units with efficiency level around 50\% is around 5 minutes. However, due to extremely high waiting times, even this service time has a target value of 2 minutes. This is possible as the medicines are already prepared and just need to be handed over to the patients. Therefore, this process could be further speeded up. However, it can be observed that patients have to wait for nearly 4 hours (in this case especially) just to collect medicines which hardly takes 3 minutes on average.

For units of analysis which have efficiency levels of nearly 90\%, such as P22, P87 and P120, it can be seen that the target values for queue length 1 is between 6 and 10 while that of queue length 2 is between 14 and 19. These results are different from those units which have efficiency levels of less than $50 \%$ as the target values are much lower than the actual values. Wait 2 has high values of nearly two hours for these units. However, for patients with around $90 \%$ efficiency, this waiting time is at most around an hour and a half..

The results show the effectiveness of the DEA model for identifying queuing problems in a busy public hospital. The values indicated by $100 \%$ efficient units (patients) displays the input values which can act as a benchmark for the inefficient units in order to render the queuing system efficient. The comparison among the actual and target values of wait times and other related queuing variables for different patients were useful in identifying the high and low values for all variables which rendered the 'whole' queue system inefficient. This information provided by DEA analysis proved to be extremely useful for the administrators as it provides evidence that certain patients have waiting time and other values as compared to others, which leads to a varying efficiency level of the queue system as a whole. DEA modelling in this regard, provided a comprehensive analysis of the queuing process, by evaluating the pathway followed by each individual patient. Therefore, DEA modelling allowed for identifying the wait times and other related factors for each patient separately. Most of the other OR techniques rely on average values which lack this level of detail as provided by DEA, by assessing the wait times of each patient. The patient flow system in public hospitals of developing countries is complex since all patients are walk-in and the number of patients is not fixed, leading to extreme variability in results. This in-depth analysis is crucial since the management can identify the 
varying wait times and other related factors so that they can take appropriate measures considering the whole queuing process, with information about the pathway followed by each patient.

\section{Conclusion and Recommendations}

The current study represents a distinctive application of DEA for queue management. The main objective is to develop a DEA model for assessing the queuing system of an Outpatients' department of a large public hospital in a developing country, where patients do not have pre-booked appointments. The analysis of this model plays a vital role in providing information to the hospital management about the extensive waiting times and associated factors that need to be addressed in order to improve the queuing system. Mainly, the results of the proposed model showed that the units which have less than $50 \%$ efficiency level have high waiting times. The target values demonstrate that immense reduction is required in waiting time values and other associated factors in order to increase the efficiency level to $100 \%$.

Furthermore, an extended DEA model was utilized, which allowed for the inclusion of consultation time with a preference. The ability of DEA modelling to incorporate this preference information provides a more realistic representation of a service, such as healthcare. Hence, the model developed in the current study is dynamic in the sense that it can be adopted by any public hospital, with either the same or different level of priority of any variable depending on the preference by the administrators.

Considering the DEA results, the management can approach the problem of extensive waiting times by adopting appropriate staff scheduling strategies. For instance, more staff members (GDMOs, pharmacists and other medical/non-medical personnel) are required to be present during the busiest time periods to cater for the high patient flow. Therefore, some additional information regarding the patient flow during different times of a day or different days of the week is required to identify the busiest times. The consultation might be reduced by identifying different activities that take place during this time. It might be possible that these routine tasks (such as temperature, blood pressure, other pre-diagnosis information from the patient etc) are conducted prior to when the 'actual' consultation starts. This will allow for proper effective treatment of the patients, leading to increased satisfaction. The analysis has shown that long waiting times are involved at the pharmacy. Therefore, it might be possible to set up a small pharmacy in the Outpatients' department consisting of the most frequently prescribed medicines. This will greatly reduce the load in the main Pharmacy. The main Pharmacy can be utilized to provide more uncommon or rare medicines. In this way, the flow of patients will be distributed, hence reducing the waiting times. The current study provides evidence of the usefulness of DEA modelling for queuing analysis. However, this is the first step to assess a bottlenecked patient flow system in a developing country, using DEA analysis. A detailed study 
specifically aiming at evaluating some other factors affecting the queuing system in a developing country hospital with additional supporting data is required, in order to provide specific recommendations for improvement.

\section{References}

Aboueljinane, L., Sahin,E. and Jemai, Z. (2013), A Review on Simulation Models Applied to Emergency Medical Service Operations, Computers and Industrial Engineering, 66 (4): 734-750.

Adeleke, R. A., Ogunwale, O.D. and Halid, O.Y. (2009), Application of Queuing Theory to Waiting Time of Out-Patients in Hospitals, The Pacific Journal of Science and Technology, 10 (2): 270-274.

Akazili, J., Adjuik, M., Appiah, C. J. and Zere, E. (2008), Using Data Envelopment Analysis to Measure the Extent of Technical Efficiency of Public Health Centers in Ghana, Bio Med Central Ltd. 20 (2): 232-248.

Al-Shammari, M. (1999), A Multi-criteria Data Envelopment Analysis Model for Measuring the Productive Efficiency of Hospitals, International Journal of Operations \& Production Management, 19 (9): 879-891.

Ashton, R., Hague, L., Brandreth, M., Worthington, D. \& Cropper, S. (2005), A Simulation-based Study of a NHS Walk-in Centre, Journal of Operational Research Society, 56 (2): 153-161.

Athanassopoulos, A.D., Lambroukos, N. and Seiford, L. (1999), Data Envelopment Scenario Analysis for Setting Targets to Electricity Generating Plants, European Journal of Operational Research, 115 (3): 413 428.

Babes, M. and Sarma, G.V. (1991), Outpatient Queues at the Ibn-Rochd Health Centre, Journal of the Operational Research Society, 42 (10): 845-855.

Banker, R. D., Conrad, R.F. and Strauss, R.P. (1986), A Comparative Application of Data Envelopment Analysis and Translog Methods: An Illustrative Study of Hospital Production,

Banker, R.D., Charnes, A. and Cooper, W.W. (1984), Some Models for Estimating Technical and Scale Efficiencies in Data Envelopment Analysis, Management Science, 30 (9): 1078-1092.

Bhattacharjee, P. and Ray, P.K. (2014), Patient Flow Modelling and Performance Analysis of Healthcare Delivery Processes in Hospitals: A Review and Reflections, Computers and Industrial Engineering, 78: 299-312.

Biju, M.K. and Naeema, K. (2011), Application of Queuing Theory in Human Resource Management in Healthcare, In: ICOQM-10, pp. 1019-1027.

Blank, J.L.T. and Van Hurst, B.L. (2011), Governance and Performance: The Performance of Dutch Hospitals Explained by Governance Characteristics, Journal of Medical Systems, 35 (5): 991-999.

Brahimi, M. and Worthington, D.J. (1991), Queuing Models for Outpatient Appointment Systems: A Case Study, Journal of Operational Research Society, 42 (9): 733-746.

Brailsford, S.C., Lattimer, V.A., Tarnaras, P. and Turnbull J.C. (2004), Emergency and On-demand Healthcare: Modeling a Large Complex System, Journal of Operational Research Society, 55, Case-Oriented Paper: pp. 34-42.

Butler, T.W. and Li, L. (2005), The Utility of Returns to Scale in DEA Programming: An Analysis of Michigan Rural Hospitals, European Journal of Operational Research, 161 (2): 469-477.

Bwana, K.M. (2015), Measuring Technical Efficiency of Faith Based Hospitals in Tanzania: An Application of Data Envelopment Analysis (DEA), Research in Applied Economics, 7(1): 1-12.

Byrnes, P. and Valdmanis, V. (1993), Analyzing Technical and Allocative Efficiency of Hospitals, In Data envelopment analysis: Theory, methodology and applications, edited by A. Charnes, W. W. Cooper, A. Y. Lewin, and L. M. Seiford. Boston: Kluwer.

Cayirli, T. and Gunes, E.D. (2014), Outpatient Appointment Scheduling in Presence of Seasonal Walk-ins, Journal of the Operational Research Society, 65: 512-531.

Cayirli, T. and Veral, E. (2003), Outpatient Scheduling in Healthcare: A Review of Literature, Journal of Medical Systems, 35 (5): 1075-1083. 
Chang, H., Cheng, M.A. and Das, S. (2004), Hospital Ownership and Operating Efficiency: Evidence from Taiwan, European Journal of Operational Research, 159 (2): 513-527.

Charnes, A., Cooper, W.W. and Rhodes, E. (1978), Measuring the Efficiency of Decision Making Units, European Journal of Operational Research, 2 (6): 429-444.

Charnes, A. and Cooper, W.W. (1962), Programming with Linear Fractional Functionals, Naval Research Logistics Quarterly, 9 (3-4): 181-185.

Chilingerian, J.A. and Sherman, H.D. (1997), DEA and Primary care Physician Report Cards: Deriving Preferred Practice Cones from Managed care Service Concepts and Operating Strategies, Annals of Operations Research, 73: 35-66.

Chuang, C.L., Chang, P.C. and Lin, R.H. (2011), An Efficiency Data Envelopment Analysis Model Reinforced by Classification and Regression Tree for Hospital Performance Evaluation, Journal of Medical Systems, 35 (5): 1075-1083.

Cooper, W.W., L.M. Seiford and J. Zhu (2004), "Data Envelopment Analysis: Models and Interpretations", Chapter 1:1-39, in W.W. Cooper, L.M. Seiford and J. Zhu, eds, Handbook on Data Envelopment Analysis, Kluwer Academic Publisher, Boston, 2004, pp. 3-4.

Cooper, W.W., Seiford, L.M. and Tone, K. (2007), Data Envelopment Analysis: A Comprehensive Text with Models, Applications, References and DEA-Solver Software, $2^{\text {nd }}$ Edition, Springer, New York.

Cote, M.J. (1999), Patient Flow and Resource Utilization in an Outpatient Clinic, Socio-Economic Planning Sciences, 33 (3): 231-245.

Dotoli, M., Epicoco, N., Falagario, M. and Sciancalepore, F. (2015), A Cross-Efficiency Fuzzy Data Envelopment Analysis Technique for Performance Evaluation of Decision Making Units Under Uncertainty, Computers and Industrial Engineering, 79: 103-114.

Emrouznejad, A. and Cabanda, E. (2014), "Managing Service Productivity: Uses of Frontier Efficiency Methodologies and MCDM for Improving Service Performance." In the series of "International Series in Operations Research \& Management Science”, Springer-Verlag, ISBN 978-3-662-43436-9.

Gunal, M.M. (2012), A Guide for Building Hospital Simulation Models, Health Systems, 1: 17-25.

Ersoy, K., Kavuncubasi, S. Ozcan, Y.A., and Harris II, J.M. (1997), Technical Efficiencies of Turkish Hospitals: DEA Approach, Journal of Medical Systems, 21 (2): 67-74.

Farrell, M.J. (1957), The Measurement of Productive Efficiency, Journal of the Royal Statistical Society: Series A (General), 120 (3): 253-290.

Feldman, J., Liu, N., Topaloglu, H., and Ziya, S. (2014), Appointment Scheduling Under Patient Preference and No-show Behavior, Operations Research, 62(4): 794-811.

Fetter, R.B. and Thompson, J.D. (1966), Patients' Waiting Time and Doctors' Idle Time in the Outpatient Setting, Health Services Research, 1 (1): 66-90.

Flokou, A., Kontodimopoulos, N. and Niakas, D. (2011), Employing Post-DEA Cross-evaluation and Cluster Analysis in a Sample of Greek NHS Hospitals, Journal of Medical Systems, 35 (5): 1001-1014.

Fomundam, S. and Hermann, J.W. (2007), A Survey of Queuing Theory Applications in Healthcare, Digital Repository at the University of Maryland, Available at: http://hdl.handle.net/1903/7222. [Accessed: 19 July 2013].

Gerdtham, U. G., Löthgren, M., Tambour, M. and Rehnberg, M. (1999). Internal Markets and Health Care Efficiency: A Multiple-output Stochastic Frontier Analysis, Health Economics, 8 (2): 151-164.

Golany, B. (1988), An Interactive MOLP Procedure for the Extension of DEA to Effectiveness Analysis, Journal of the Operational Research Society, 39 (8): 725-734.

Griffiths, J.D., Price-Lloyd, N., Smithies, M. and Williams, J.E. (2005), Modeling the Requirement for Supplementary Nurses in an Intensive Care Unit, Journal of Operational Research Society, 56 (2): 126133.

Grosskopf, S. and Valdmanis, V. (1987), Measuring Hospital Performance: A Nonparametric Approach, Journal of Health Economics, 6 (1): 89-107. 
Gul, M. and Guneri, A.F. (2015), A Comprehensive Review of Emergency Department Simulation Applications for Normal and Disaster Conditions, Computers and Industrial Engineering, 83: 327-344.

Gunal, M. and Pidd, M. (2010), Discrete-event Simulation for Performance Modeling in Healthcare: A Review of the Literature, Journal of Simulation, 4: 42-51.

Halme, M., Joro, T., Korhonen, P., Salo, S. and Wallenius, J. (1999). A Value Efficiency Approach to Incorporating Preference Information in Data Envelopment Analysis, Management Science, 45 (1): 103115.

Harper, P.R. and Gamlin, H.M. (2003), Reduced Outpatient Waiting Times with Improved Appointment Scheduling: A Simulation Modeling Approach, OR Spectrum, 2 (2): 207-222.

Harrison, J.P., Coppola, M.N. and Wakefield, M. (2004), Efficiency of Federal Hospitals in the United States, Journal of Medical Systems, 28 (5): 411-422.

Hassin, R. and Mendel, S. (2008), Scheduling Arrivals to Queues: A Single-Server Model with No- shows, Management Science, 54 (3): 565-572.

Hill-Smith, I. (1989), Mathematical Relationship Between Waiting Times and Appointment Interval for Doctors and Patients, Journal of the Royal College of General Practitioners, 39 (329): 492-494.

Hollingsworth, B. (2012), Revolution, Evolution or Status-quo? Guidelines for Efficiency Measurement in Healthcare, Journal of Productivity Analysis, 37(1): 1-5.

Hollingsworth, B. (2008), The Measurement of Efficiency and Productivity of Healthcare Delivery, Health Economics, 17 (10): 1107-1128.

Hollingsworth, B. and Parkin, D. (1995), The Efficiency of Scottish Acute Hospitals: An Application of Data Envelopment Analysis, IMA Journal of Mathematics Applied in Medicine and Biology, 12 (3-4): 161-173.

Huang, Y.G. and McLaughlin, C.P. (1989), Relative Efficiency in Rural Primary Health care: An Application of Data Envelopment Analysis, Health Services Research, 24 (2):143-158.

Huarng, F. and Lee, M.H. (1996), Using Simulation in Outpatient Queues: A Case Study, International Journal of Healthcare Quality Assurance, 9 (6): 21-25.

Jun, J.B., Jacobson, S.H. and Swisher, J.R. (1999), Application of Discrete-event Simulation in Healthcare Clinics: A Survey, Journal of the Operational Research Society, 50 (2): 109-123.

Jehu-Appiah, C., Sekidde, S., Adjuik, M., Akazili, J., Almeida, S.D., Nyonator, F., Baltussen, R., Asbu, E.Z. and Kirigia, J.M. (2015), Ownership and Technical Efficiency of Hospitals: Evidence from Ghana Using Data Envelopment Analysis, Cost Effectiveness and Resource Allocation, 12:9, Available at: http://www.resource-allocation.com/content/12/1/9 [Accessed: 8 June 2015]

Kang, H., Nembhard, H.B. and DeFlitch, C. (2014), Identifying Emergency Department Efficiency Frontiers and the Factors Associated with Their Efficiency Performance, Proceedings of the 2014 Industrial and Systems Engineering Research Conference, (Guan, Y and Liao, H eds).

Kawaguchi, H, Tone, K. and Tsutsui, M. (2014), Estimation of the Efficiency of Japanese Hospitals Using a Dynamic and Network Data Envelopment Analysis Model, Healthcare Management Science, 17: 101-112.

Khori, V., Changizi, S., Biuckians, E., Keshtkar, A., Alizadeh, A. M., Mohaghgheghi, A. M. and Rabie, M. R. (2012), Relationship Between Consultation Length and Rational Prescribing of Drugs in Gorgan City, Islamic Republic of Iran, Eastern Mediterranean Health Journal, 18 (5): 480-486.

Kirigia, J.M., Emrouznejad, A., Cassoma, B., Asbu, E.Z. and Barry, S. (2008), A Performance Assessment Method for Hospitals: The Case of Municipal Hospitals in Angola, Journal of Medical Systems, 32 (6): 509-519.

Kirigia, J.M., Emrouznejad, A., Sambo, L.G., Munguti, N. and Liambila, W. (2004), Using Data Envelopment Analysis to Measure the Technical Efficiency of Public Health Centers in Kenya, Journal of Medical Systems, 28 (2): 155-166.

Klassen, K.J. and Rohleder, T.R. (1996), Scheduling Outpatient Appointments in a Dynamic Environment, Journal of Operations Management, 14 (2): 83-101.

Klassen, K.J. and Yoogalingham, R. (2009), Improving Performance in Outpatient Appointment Services with a Simulation Optimization Approach, Production and Operations Management. 18 (4): 447-458. 
Konrad, R., DeSotto, K., Grocela, A., McAuley, P., Wang, J., Lyons, J. and Bruin, M. (2013), Modelling the Impact of Changing Patient Flow Processes in an Emergency Department: Insights from a Computer Simulation Study, Operations Research for Health Care, 2 (4): 66-74.

Kose, T., Uckun, N. and Girginer, N. (2014), An Efficiency Analysis of the Clinical Departments of a Public Hospital in Eskisehir by Using DEA, Global Journal on Advances in Pure and Applied Sciences, 4: 252258.

Lakshmi, C and Sivakumar, A.I. (2013), Application of Queuing Theory in Healthcare: A Literature Review, Operations Research for Healthcare, 2 (1-2): 25-39.

Lane, D.C., Monefeldt, C. and Rosenhead, J.V. (2000), Looking in the Wrong Place for Healthcare Improvements: A System Dynamics Study of an Accident and Emergency Department, Journal of Operational Research Society, 51 (5): 518-531.

Lee, H. and Kim, C. (2014), Benchmarking of Service Quality with Data Envelopment Analysis, Expert Systems with Applications, 41 (8): 3761-3768.

Lewis, H.F., Sexton, T.R. and Dolan, M.A. (2011), An Efficiency-Based Multicriteria Strategic Planning Model for Ambulatory Surgery Centers, Journal of Medical Systems, 35 (5): 1029-1037.

Linna, M. (1998), Measuring Hospital Cost Efficiency with Panel Data Models, Health Economics, 7 (5): 415 427.

Liu, J., Ding, F.F. and Lall, V. (2000), Using Data Envelopment Analysis to Compare Suppliers for Supplier Selection and Performance Improvement, Supply Chain Management: An International Journal, 5 (3): 143-150.

Liu, J.S., Lu, L.Y.Y., Lu, W. and Lin, B.J.Y. (2013b), A Survey of DEA Applications, Omega, 41 (5): $893-902$.

Liu, J.S., Lu, L.Y.Y., Lu,W. and Lin, B.J.Y. (2013a), Data Envelopment Analysis 1978-2010: A Citation-based Literature Survey, Omega, 41 (1): 3-15.

Magnussen, J. (1996), Efficiency Measurement and the Operationalization of Hospital Production, Health Services Research, 31 (1): 21-37.

Mankowska, D.S., Meisel, F. and Bierwirth, C. (2014), The Home Healthcare Routing and Scheduling Problem with Interdependent Services, Healthcare Management Science, 17: 15-30.

Manzi, A, Magge H, Hedt-Gauthier, B.L., Michaelis, A.P., Cyamatare, F.R., Nyirazinyoye, L, Hirschhorn, L.R. and Ntaganira, J. (2014), Clinical Mentorship to Improve Pediatric Quality of Care at the Health Centers of Rural Rwanda: A Qualitative Study of Perceptions and Acceptability of Health Workers, BMC Health Services Research, 14(275), Available at: http://www.biomedcentral.com/1472-6963/14/275 [Accessed: 27 Sept 2015]

Martic, M. and Savic, G. (2001). An Application of DEA for Comparative Analysis and Ranking of Regions in Serbia with Regards to Social-Economic Development, European Journal of Operational Research, 132 (2): 343-356.

Masiye, F., Kirigia, J.M., Emrouznejad, A., Sambo, L.G., Mounkaila, A., Chimfwembe, D. and Okello, D. (2006), Efficient Management of Health Centres Human Resources in Zambia, Journal of Medical Systems, 30 (6): 473-481.

Matta, M.E. and Patterson, S.S. (2007), Evaluating Multiple Performance Measures Across Several Dimensions at a Multi-facility Outpatient Center, Healthcare Management Science, 10 (2): 173-194.

May, J.H., Spangler, W.E. and Strum, D.P. (2011), The Surgical Scheduling Problem: Current Research and Future Opportunities, Production and Operations Management, 20 (3): 392-405.

Mayhew, L. and Smith, D. (2008), Using Queuing Theory to Analyse the Government's 4-h Completion Time Target in Accident and Emergency Departments, Healthcare Management Science, 11 (1): 11-21.

Mehandiritta, R. (2011), Applications of Queuing Theory in Healthcare, International Journal of Computing and Business Research, 2 (2): 2229-6166.Mensah, J., Asamoah, J. and Tawiah, A.A. (2015), Optimizing Patient Flow and Resource Utilization in Outpatient Clinic: A Comparative Study of Nkawie Government Hospital and Aniwaa Health Center, Journal of Applied Business and Economics, 16 (3): 181188.Nunamaker, T.R. (1983), Measuring Routine Nursing Service Efficiency: A Comparison of Cost per Day and Data Envelopment Analysis Models'. Health Services Research, 18 (2): 183-208. 
O’Keefe, R.M. (1998), 'Investigating Outpatient Departments: Implementable Policies and Qualitative Approaches, Journal of Operational Research Society, 36 (8): 705- 712.

O’Neill, L., Rauner, M., Heidenberger, K. and Kraus, M. (2008), A Cross-National Comparison and Taxonomy of DEA-based Hospital Efficiency Studies, Socio-Economic Planning Sciences, 42 (3): 158-189.

Osman, I.H., Berbary, L.N., Sidani, Y., Al-Ayoubi, B. and Emrouznejad, A. (2011), Data Envelopment Analysis Model for the Appraisal and Relative Performance Evaluation of Nurses at an Intensive Care Unit, Journal of Medical System, 35 (5): 1039-1062.

Ouellette, P. and Vierstraete, V. (2004), Technological Change and Efficiency in the Presence of Quasi- Fixed Inputs: A DEA Application to the Hospital Sector, European Journal of Operational Research, 154 (3): 755-763.

Parkin, D. and Hollingsworth, B. (1997), Measuring Production Efficiency of Acute Hospitals in Scotland, 1991-94: Validity Issues in Data Envelopment Analysis, Applied Economics, 29 (11): 1425-1433.

Prior, D. (2006). Efficiency and Total Quality Management in Healthcare Organizations: A Dynamic Frontier Approach, Annals of Operations Research, 145 (1): 281-299.

Proudlove, N.C., Black, S., and Fletcher, A. (2007), OR and the Challenge to Improve the NHS: Modeling for Insight and Improvement in In-patient Flows, Journal of the Operational Research Society, 58 (2): 145158.

Puig-Junoy, J. (2000), Partitioning Input Cost Efficiency into its Allocative and Technical Components: An Empirical DEA Application to Hospitals, Socio Economic Planning Sciences. 34 (3): 199-218.

Ramanathan, R. (2005), Operations Assessment of Hospitals in the Sultanate of Oman, International Journal of Productions and Operations Management, 25 (1): 39-54.

Ramirez-Valdivia, M.T., Maturana, S. and Salvo-Garrido, S. (2011), A Multiple-stage Approach for Performance Improvement of Primary Healthcare Practice, Journal of Medical Systems, 35 (5): 1015-1028.

Ridge, J.C., Jones, S.K., Nielsen, M.S. and Shahani, A.K. (1998), Capacity Planning for Intensive Care Units, European Journal of Operational Research, 105 (2): 346-355.

Rising, E., Baron, R. and Averill, B. (1973), A System Analysis of a University Health Service Outpatient Clinic, Operations Research, 21 (5): 1030-1047.

Rouse, P., Harrison, J. and Turner, N. (2011), Cost and Performance: Complements for Improvement, Journal of Medical Systems, 35 (5): 1063-1074.

Salinas-Jimenez, J. and Smith, P. (1996), Data Envelopment Analysis Applied to Quality in Primary Healthcare, Annals of Operations Research, 67 (1): 141-161.

Sherman, H.D. (1984), Improving the Productivity of Service Businesses, Sloane Management Review, 25 (3): $11-23$.

Silva, F. and Serra, D. (2008), Locating Emergency Services with Different Priorities: The Priority Queuing Covering Location Problem, Journal of the Operational Research Society, 59 (9): 1229-1238.

Silvester, K., Lendon, R., Bevan, H., Steyn, R. and Walley, P. (2004), Reducing Waiting Times in the NHS: Is Lack of Capacity the Problem? Clinician in Management, 12: Academic Paper, 1-7.

Sorup, C.M., Estay, D.S., Jacobsen, P. and Anderson, P.D. (2015), Balancing Patient Flow and Returning Patients: A System Dynamics Study on Emergency Department Crowding Factors, Healthcare Management Science, Available at: http://orbit.dtu.dk/ws/files/108550877/Balancing_patient.pdf [Accessed: 8 June 2015]

Thanassoulis, E. (2001), Introduction to the Theory and Application of Data Envelopment Analysis: A Foundation Text with Integrated Software, Kluwer Academic Publishers, USA.

Thanassoulis, E. and Dunstan, P. (1994), Guiding Schools to Improved Performance Using Data Envelopment Analysis: An Illustration with Data from a Local Education Authority, Journal of the Operational Research Society, 45 (11): 1247-1262.

Thanassoulis, E. and Dyson, R.G. (1992), Estimating Preferred Target Input-output Levels Using Data Envelopment Analysis, European Journal of Operational Research, 56 (1):80-97. 
Thanassoulis, E., Boussofiane, A. and Dyson, R.G. (1995), Exploring Output Quality Targets in the Provision of Perinatal Care in England Using Data Envelopment Analysis, European Journal of Operational Research, 80 (3): 588-607.

Thanassoulis, E., Boussofiane, A. and Dyson, R.G. (1996), A Comparison of DEA and Ratio Analysis as Tools for Performance Measurement, Omega, 24 (3): 229-244.

Tsai, P.F. and Molinero, C.M. (2002), A Variable Returns to Scale Data Envelopment Analysis Model for the Joint Determination of Efficiencies with an Example of the UK Health Service, European Journal of Operational Research, 141 (1): 21-38.

Valdmanis, V. (1992), Sensitivity Analysis for DEA Models: An Empirical Example Using Public Vs NFP Hospitals, Journal of Public Economics, 48 (2): 185-205.

Wagner, J.M., Shimshak, D.G. and Novak, M.A. (2003), Advances in Physician Profiling: The Use of DEA, Socio-Economic Planning Sciences, 37 (2): 141-163.

Welch, J.D. (1964), Appointment Systems in Hospitals and General Practice: Appointment Systems in Hospital Outpatient Departments, Journal of the Operational Research Society, 15 (3):224-232.

Weng,S.J., Wu, T., Blackhurst J. and Mackulak, G. (2009), An Extended DEA Model for Hospital Performance Evaluation and Improvement, Health Services and Outcomes Research Methodology, 9 (1): 39-53.

Worthington, A.C. (2004), Frontier Efficiency Measurement in Healthcare: A Review of Empirical Techniques and Selected Applications, Medical Care Research and Review, 61 (2):135-170.

Yeboah, E.K. and Thomas, M.E. (2010), A Cost-effective Way of Reducing Outpatient Clinic Waiting Times: How We Did It, Internal Journal of Healthcare Administration, 7 (1).

Zere, E., McIntyre, D., and Addison, T. (2001), Technical Efficiency and Productivity of Public Sector Hospitals in Three South African Provinces, South African Journal of Economics, 69 (2):336-358.

Zhu, J. (1996), Data Envelopment Analysis with Preference Structure, Journal of the Operational Research Society, 47 (1): 136-150.

Zhu, Z., Heng, B.H. and Teow, K.L. (2012), Analysis of Factors Causing Long Patient Waiting Time and Clinic Overtime in Outpatient Clinics, Journal of Medical Systems, 36 (2): 707-713.

Zuckerman, S., Hadley, J. and Iezzoni, L. (1994), Measuring Hospital Efficiency with Frontier Cost Functions, Journal of Health Economics, 13 (3):255-280. 